\title{
Article \\ Study on the Springback Effect and Surface Property for Ultrasonic-Assisted Incremental Sheet Forming of Aluminum Alloy
}

\author{
Yujing Sun ${ }^{1,2, *}$, Zhenyun $\mathrm{Lu}^{1,2}$, Chao $\mathrm{Li}^{1,2}$, Rongtao Wang ${ }^{1}$ and Weidong Zhai ${ }^{3}$ \\ 1 School of Mechanical and Automotive Engineering, Qilu University of Technology (Shandong Academy \\ of Sciences), Jinan 250353, China; 1043118182@stu.qlu.edu.cn (Z.L.); 201701010180@stu.qlu.edu.cn (C.L.); \\ 1043118211@stu.qlu.edu.cn (R.W.) \\ 2 Shandong Institute of Mechanical Design and Research, Jinan 250353, China \\ 3 School of Mechanical Engineering, Shandong University, Jinan 250061, China; zhaiweidong.ss@crrcgc.cc \\ * Correspondence: sunyujing@qlu.edu.cn
}

check for updates

Citation: Sun, Y.; Lu, Z.; Li, C.; Wang, R.; Zhai, W. Study on the Springback Effect and Surface Property for Ultrasonic-Assisted Incremental Sheet Forming of Aluminum Alloy. Symmetry 2021, 13, 1217. https:// doi.org/10.3390/sym13071217

Academic Editor: Alexey Lukoyanov

Received: 3 June 2021

Accepted: 6 July 2021

Published: 7 July 2021

Publisher's Note: MDPI stays neutral with regard to jurisdictional claims in published maps and institutional affiliations.

Copyright: (c) 2021 by the authors. Licensee MDPI, Basel, Switzerland. This article is an open access article distributed under the terms and conditions of the Creative Commons Attribution (CC BY) license (https:// creativecommons.org/licenses/by/ $4.0 /)$.

\begin{abstract}
The effect of ultrasonic vibration on the springback effect and surface property for ultrasonic-assisted incremental sheet forming of aluminum alloy were discussed. A series of experiments were established to explore the ultrasonic vibration on the surface property and springback effect of symmetrical aluminum alloy sheet in order to facilitate analysis of experimental results. It is obtained that the application of ultrasonic vibration can reduce the springback effect. The surface waviness feature aluminum alloy becomes weaker with the continuous increase of ultrasonic amplitude and the surface topography tends to be smoother. In addition, the application of ultrasonic vibration can reduce the surface hardness and promote the surface residual stress distribution to be more uniform. The findings provide an experimental basis for further investigation of the mechanisms of the ultrasonic-assisted incremental sheet forming process.
\end{abstract}

Keywords: springback effect; surface property; ultrasonic-assisted incremental sheet forming; aluminum alloy

\section{Introduction}

Compared with the traditional process, ultrasonic-assisted plastic forming can reduce the forming load, improve the surface quality of parts, and decrease the springback of sheet, which is an advanced plastic forming process with broad application prospects. In recent years, many scholars have studied the theoretical mechanism of metal ultrasonic vibration plastic forming [1-3]. Li et al. [4] discussed that the material flow and deformation behavior during ultrasonic-assisted incremental forming of straight grooves. Ashida et al. [5] presented that ultrasonic vibration can help reduce wrinkles and cracks in stamping process through experiments and simulations. Hung et al. [6] found that the friction and forming forces were reduced by applying ultrasonic vibration in cold or hot heading process. A numerical simulation model that could effectively consider the softening effect of ultrasonic plasticity was established based on the variational model of porous metal plasticity to study the mechanism of ultrasonic action on reducing friction and forming force [7]. Siu et al. [8] considered that ultrasonic softening effect was not only due to the decrease of friction force, but also the change of material properties under the excitation of ultrasonic vibration. They found that ultrasonic vibration was helpful to improve the formation of subgrains in the hardness indentation experiment of polycrystalline aluminum. In addition, Dutta et al. [9] studied the evolution mechanism of microstructure of DC04 mild steel in ultrasonic vibration tensile test, and observed that when the tensile strain was $20 \%$, the micro-dislocation density, substructure of the sample and the proportion of grain boundary at a small angle were significantly reduced compared with the sample without ultrasonic 
vibration. Yao et al. [10] observed the effect of stress softening and residual hardening caused by ultrasonic vibration through ultrasonic upsetting experiment.

Incremental sheet forming is an emerging sheet forming technology that is suitable for complex three-dimensional shapes, which has made great progress since the concept was proposed by Leszak [11] in 1967 and proven to be feasible by Kitazawa [12], which has the conception of rapid prototyping so that it has been widely applied for small quantity production in various applications $[13,14]$. However, the unsatisfied geometric accuracy and surface property of incremental sheet forming, which is mainly due to springback, which still hinders its wide industrial application $[15,16]$. At present, various strategies have been proposed with the aim to satisfy industrial requirements. Mirnia et al. [17] discussed the influences of the process parameter optimization and the forming trajectory optimization on the thickness distribution of the cone. Kim et al. [18] proposed the doublepass forming method, and the results showed that the thickness strain distribution of a final shape can be made more uniform.

Nevertheless, different strategies have their own limits, and the geometric accuracy and surface property of incremental sheet forming are unsatisfied for industrial application. At present, ultrasonic vibration has been used in tube drawing, volume forming and other plastic processing processes and has positive effects on reducing the forming force and improving the quality of forming parts, but there are few reports on the application of ultrasonic vibration in incremental sheet forming process. Therefore, it is necessary to apply ultrasonic vibration to the basis of traditional incremental sheet forming to solve the problems of low surface quality, low precision, and insufficient forming ability.

In this study, the effect of ultrasonic vibration on the springback effect and surface property for ultrasonic-assisted incremental sheet forming of aluminum alloy were discussed. A series of experiments were established to explore the ultrasonic vibration on the surface property and springback effect of aluminum alloy sheet in order to facilitate analysis of experimental results, which provided an experimental basis for further investigation of the mechanisms of the ultrasonic-assisted incremental sheet forming process.

\section{Experimental Methods}

\subsection{Experimental Setup}

The experimental setup of the ultrasonic-assisted incremental forming process, as shown in Figure 1, which includes an incremental forming process machine, an ultrasonic generator, and a vibration system consisting of of ultrasonic transducer and amplitude transformer. The ultrasonic generator converts the AC power into high frequency electrical signals to the transducer, which converts the high frequency electrical signals to mechanical vibration. Then the amplitude transmitted by the transducer is amplified by the amplitude transformer, and finally, the mechanical vibration is transmitted to the forming tool. When ultrasonic is added, the continuous signal is transformed into discrete pulse force signal, and the discontinuous contact between the forming tool and the sheet metal in the process of asymptotic forming is realized. According to the existing hardware environment, the diameter of the forming tool is $5 \mathrm{~mm}$ and maximum amplitude without loading corresponds to $15.9 \mu \mathrm{m}$ within the rated power of $100 \mathrm{~W}$. The springback detection system mainly includes high-speed contracer, controller, and PC. PC sends instructions to the controller, the controller controls the sensor for data acquisition, and the collected data is finally transmitted back to the PC for display processing.

The forming experiments utilized AA-5052 material whose chemical compositions and mechanical properties are shown in Tables 1 and 2, which are provided by manufacturer. The aluminum alloy sheet was cut into rectangle shapes with a dimension of $270 \times 190 \times 2 \mathrm{~mm}$. The sheet was installed by fixture, and processing path is symmetrical to obtain symmetrical sample to facilitate analysis of experimental results, as shown in Figure 1. The experiments were carried out at both conditions with and without ultrasonic vibration to discuss the influence of ultrasonic vibration on the incremental forming pro- 
cess. Table 3 shows the experiment parameters, and the processing path is illustrated in Figure $1 b$.
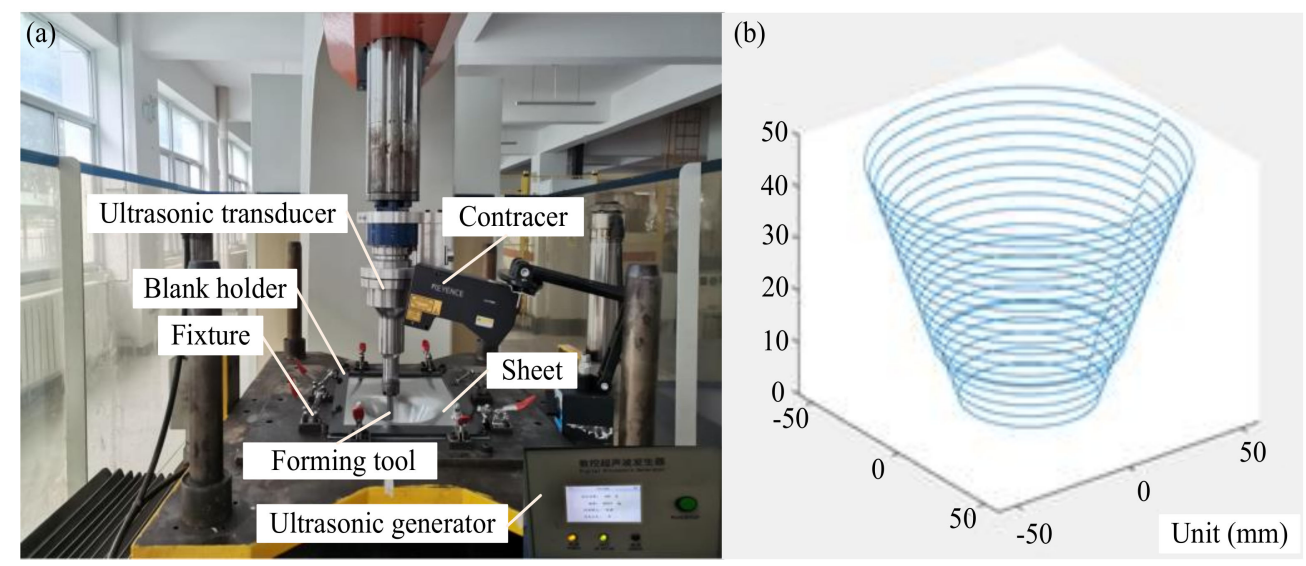

Figure 1. The experimental setup of the ultrasonic-assisted incremental forming process (a) Incremental forming process machine (b) Processing path.

Table 1. Chemical compositions of the AA-5052 material.

\begin{tabular}{cccccccccc}
\hline Material & Mg (wt \%) & Si (wt \%) & Cu (wt \%) & Zn (wt \%) & Mn (wt \%) & $\begin{array}{c}\text { Cr } \\
(\text { wt \%) }\end{array}$ & $\begin{array}{c}\text { Fe } \\
(\text { wt \%) }\end{array}$ & Others & $\begin{array}{c}\text { Al } \\
(w t ~ \%)\end{array}$ \\
\hline AA-5052 & $2.2 ~ 2.8$ & 0.25 & 0.10 & 0.10 & 0.10 & $0.15 ~ 0.35$ & 0.40 & 0.15 & Remainder \\
\hline
\end{tabular}

Table 2. Mechanical properties of the AA-5052 material.

\begin{tabular}{cccccc}
\hline Material & Young's Modulus (GPa) & Poisson's Ratio & Yield Stress (MPa) & $\begin{array}{c}\text { Ultimate Tensile Strength } \\
\text { (MPa) }\end{array}$ & $\begin{array}{c}\text { Maximum } \\
\text { Elongation }\end{array}$ \\
\hline AA-5052 & 69.3 & 0.33 & 65 & 244 & $20 \%$ \\
\hline
\end{tabular}

Table 3. The designed parameters for the ultrasonic-assisted incremental forming experiments.

\begin{tabular}{cccccc}
\hline Test No. & Tool Diameter $(\mathbf{m m})$ & Layer Feed $(\mathbf{m m})$ & Power $(\%)$ & Ultrasonic Amplitude $(\mu \mathrm{m})$ & Feed Speed $(\mathbf{m m} / \mathbf{m i n})$ \\
\hline 1 & 5 & 0.3 & 0 & 0 & 800 \\
2 & 5 & 0.3 & 40 & 1.3 & 800 \\
3 & 5 & 0.3 & 70 & 6.3 & 800 \\
4 & 5 & 0.3 & 99 & 15.9 & 800 \\
\hline
\end{tabular}

\subsection{Measurement of Springback and Surface Property}

\subsubsection{Springback Effect}

The high-speed contracer was adopted to carry out the detection research on the springback influence of symmetric rotating body, and the detection of springback is divided into the following stages:

Stage 1: measuring the springback data of unraised the tool to raising the tool to obtain the springback value after lifting the forming tool.

Stage 2: measuring the springback data of raising the tool to the released the blank holder.

Stage 3: measuring the springback data of the unraised head to releasing blank holder to obtain the final amount of springback.

The above research work has a more detailed understanding of the springback, which is beneficial to determine the springback compensation more accurately, and to realize the high precision machining of the incremental sheet forming technology. Further, the springback at different stages of the forming sheet was also explored, as shown in Figure 2. For aluminum alloy sheet, it can be divided into the forming side wall Stage (AB), the 
forming stage between the processed area and the non-processed area at the bottom of the forming tool (BC). Besides, three experiments in each group have been conducted, and the average value and square deviation of corresponding results were calculated and analyzed.

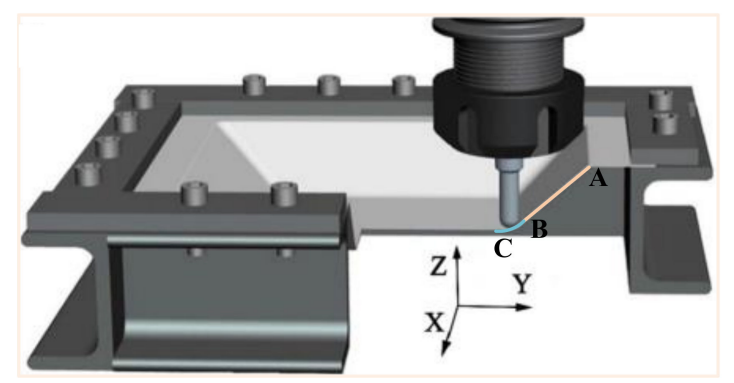

Figure 2. Measurement of springback effect at different stages of the forming sheet [19].

\subsubsection{Surface Residual Stress}

Proto IXRD residual stress meter was selected to test five points along the direction of forming depth on the side wall of the forming workpiece in contact with the forming tool and non-contact in order to explore the influence of ultrasonic vibration on the surface residual stress of the incremental sheet forming of aluminum alloy sheets, as shown in Figure 3, and each point was measured three times to improve the stability of the results for symmetrical aluminum alloy sheet.

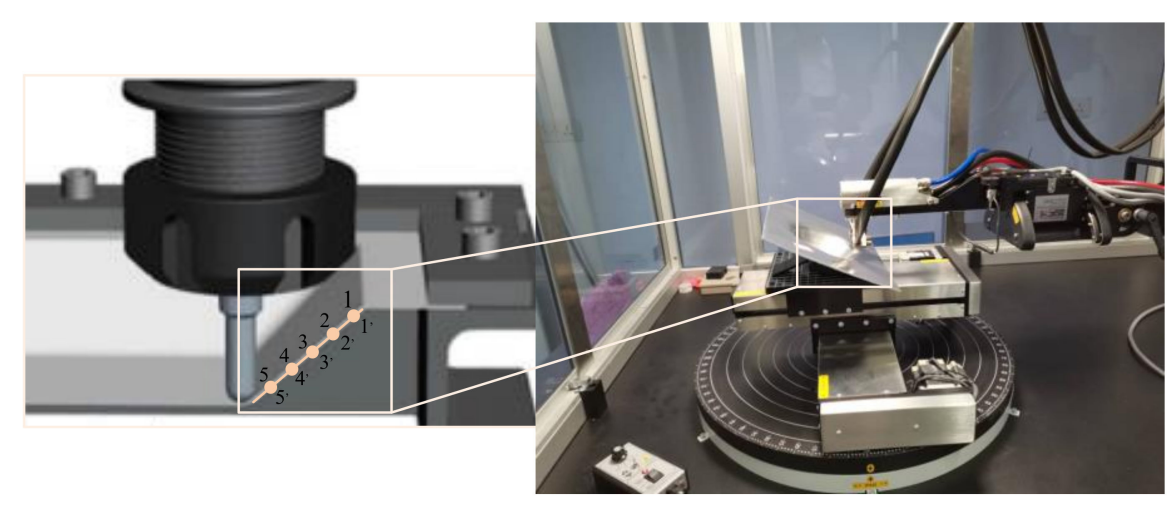

Figure 3. Measurement of surface residual stress.

\subsubsection{Measurement of Surface Topography}

The surface topography of the ultrasonic-assisted incremental sheet forming of aluminum alloy was measured by the white light interferometer (Bruker Contour Elite K), as shown in Figure 4. The side wall of symmetrical aluminum alloy sheet sample was cut off by wire cutting equipment, which was cleaned with alcohol by ultrasonic cleaning instrument, and dried by a dryer. Then the surface topography was measured by white light interferometer. The sample length was $48 \mu \mathrm{m}$ and the sample width was $35 \mu \mathrm{m}$ with a 100X objective lens. Each surface was randomly measured three times to ensure the accuracy of the experimental results. 

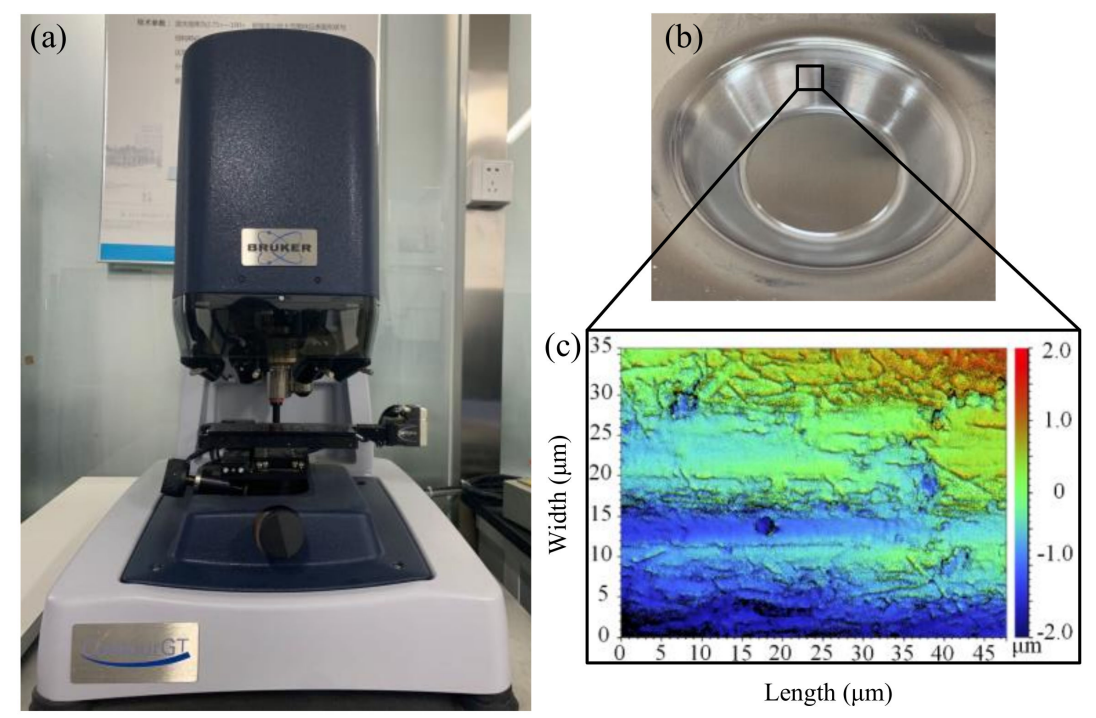

Figure 4. Measurement of surface topography (a) A white light interferometer (Bruker Contour Elite K) (b) The test samples (c) The surface topography.

\subsubsection{Measurement of Surface Hardness}

The surface hardness of the contact side wall between the aluminum alloy sheet and the forming tool was measured to investigate the influence of high frequency impact and discontinuous contact of ultrasonic vibration on the surface properties of the forming sheet. The test points are shown in Figure 5, and each point was measured three times to improve the stability of the results. The Vickers micro-hardness tester model is MH-6. The loading load during the test is $200 \mathrm{~g}$, and the loading time is $10 \mathrm{~s}$.

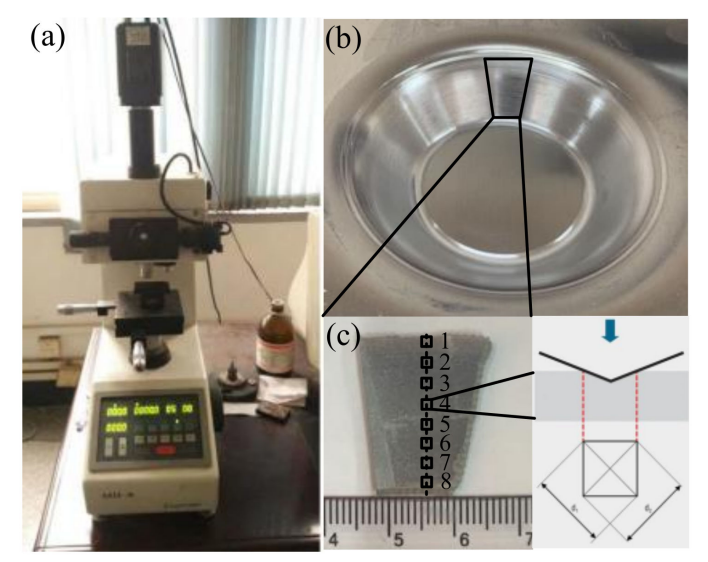

Figure 5. Measurement of surface hardness (a) The Vickers micro-hardness tester (MH-6) (b) The test samples (c) The surface hardness.

\section{Results and Discussions}

\subsection{Springback Effect}

Figure 6 presents that the springback value of the forming side wall Stage (AB) changes steadily when the ultrasonic is applied or not applied in the forming stage. The average and square deviation of the springback values were shown in Figure 7. There was a decline in the average value of springback with ultrasonic-assistance compared with that without ultrasonic, and the maximum reduction of springback was shown in Stage 3 and in $Y$ positions from $-25 \mathrm{~mm}$ to $-12 \mathrm{~mm}$ after the application of ultrasonic-assistance. 

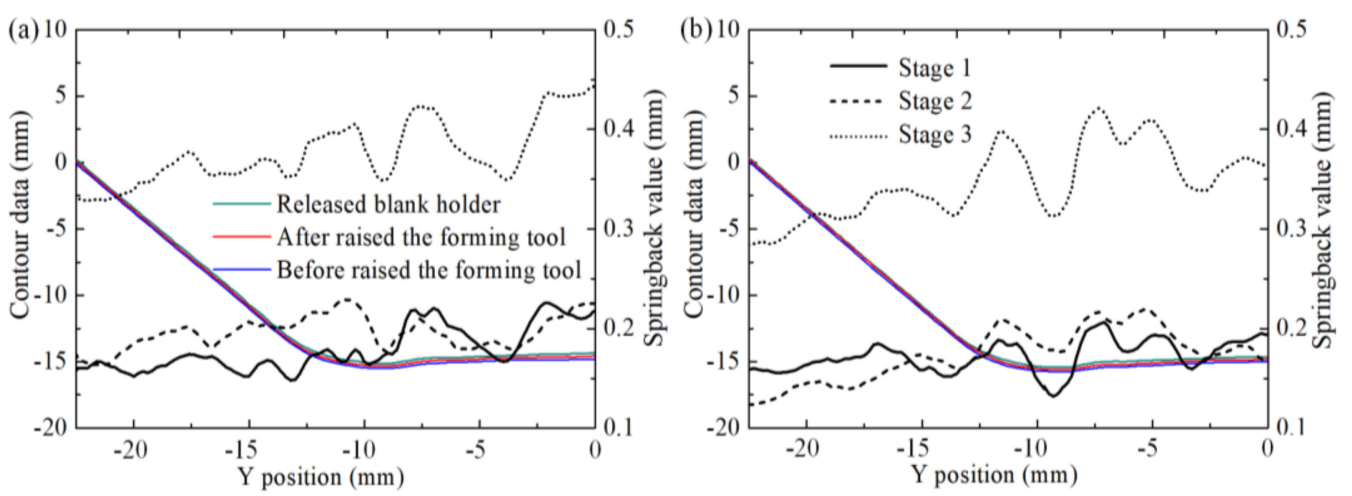

Figure 6. Typical contour data and springback values of three stages (a) Without ultrasonic and (b) With ultrasonic-assistance.

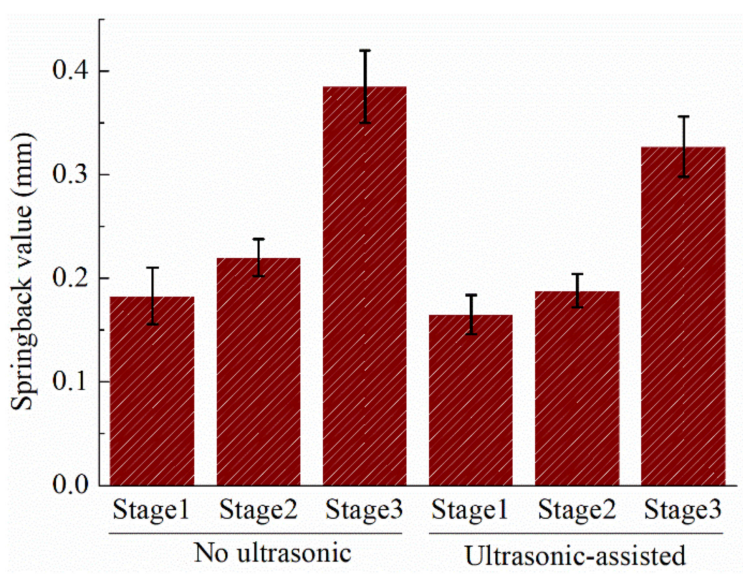

Figure 7. The average and square deviation of the springback values.

The $\mathrm{BC}$ section generates the maximum springback value after lifting the forming tool or releasing the blank holder, and the similar conclusion was obtained by Zhang et al. [20]. In previous studies, Zhai et al. [15] investigated on the forming force during ultrasonicassisted incremental sheet forming process and obtained that the forming force increases with the increase of feed depth, and the axial forming force is reduced after applying ultrasonic vibration. Incremental sheet forming process of sheet is a comprehensive mechanical phenomenon, especially in complex forming process, which is often accompanied by complex strain paths, so the springback deformation behavior is difficult to predict. To a certain extent, the application of ultrasonic vibration can reduce the springback effect.

\subsection{Surface Residual Stress}

Figure 8a shows the distribution diagram of residual stress on the side wall surface of the contact between the ultrasonic-assisted incremental sheet forming of aluminum alloy sheets and the forming tool. It can be seen that the residual stress on the side wall surface is mainly tensile stress, and the stress increases with the increase of depth.

To further analyze the effect of the ultrasonic vibration on the surface residual stress, the residual stress was measured at the test points corresponding to the side wall, which was not in contact with the sheet and the forming tool, which is depicted in Figure 8b. It can be observed that the residual stress on the surface of the non-contact side wall with the forming tool is mainly compressive stress, which decreases first and then increases with the increase of depth. On the whole, the compressive stress of the plate without ultrasonic vibration is lower than that of the plate with ultrasonic vibration. The uniform distribution of residual compressive stress caused by ultrasonic vibration can improve the fatigue life of the workpiece and reduce the scrap phenomenon caused by stress corrosion cracking. 

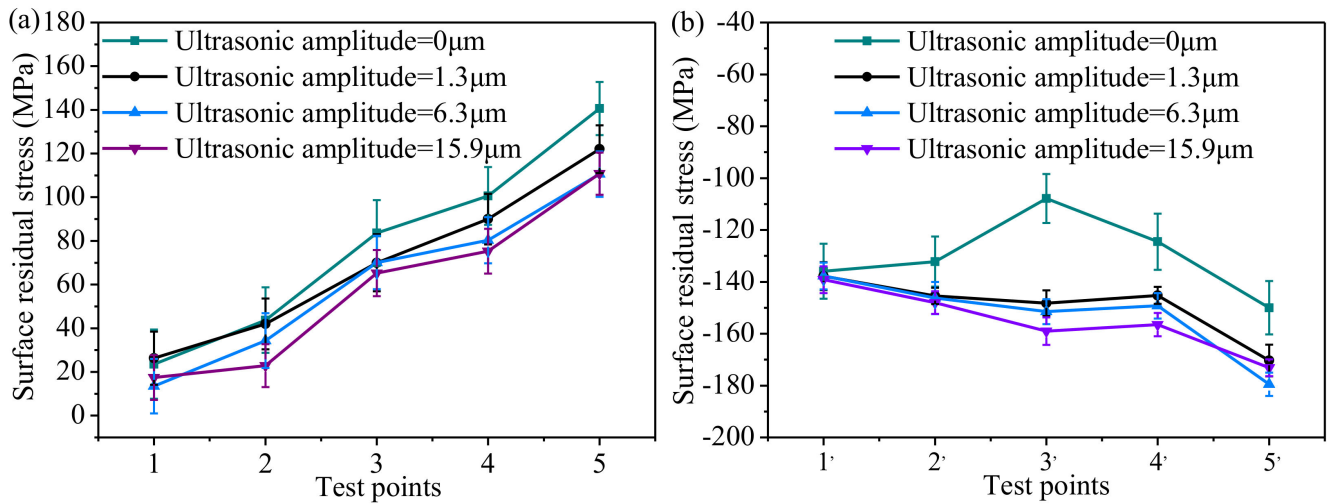

Figure 8. The distribution diagram of residual stress (a) Surface residual stress of surface contact with the sheet and the forming tool (b) Surface residual stress of non-surface contact with the sheet and the forming tool.

\subsection{Measurement of Surface Topography}

The surface topography formed in incremental sheet forming of aluminum alloy sheets with or without ultrasonic vibration is shown in Figure 9. It can be observed the horizontal waviness of the surface in Figure 9a-c, which is one of the main characteristics in incremental sheet forming. The formation of waviness is closely related to the continuous extrusion between the forming tool and the sheet, during which the plastic flow of the material is generated on the contact surface. In particular, the furrows effect from the flow on both sides of the forming tool results in this morphological feature. However, the waviness feature becomes weaker with the continuous increase of ultrasonic amplitude, which is mainly caused by the waviness feature of the contact surface gradually disappears due to the high-frequency impact of the forming tool applied ultrasonic vibration.
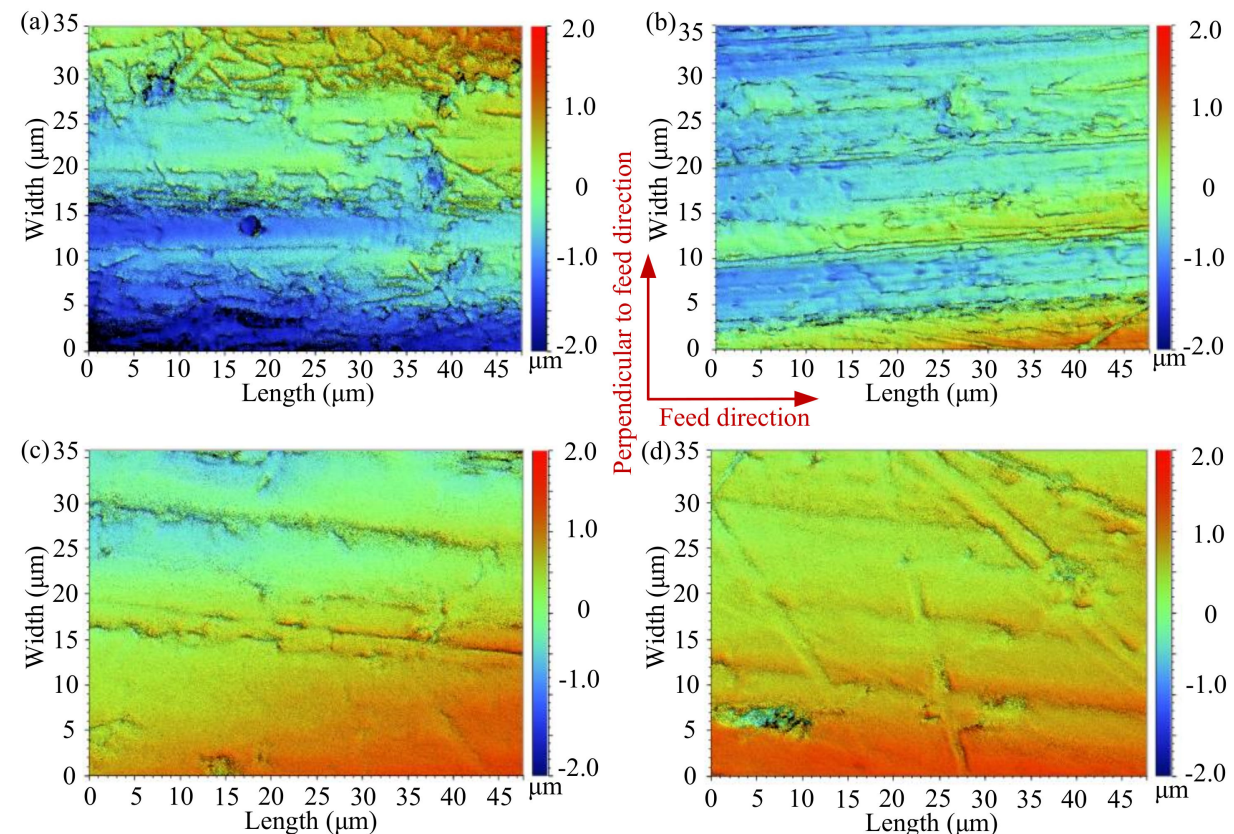

Figure 9. The surface topography with different ultrasonic amplitude during ultrasonic-assisted incremental sheet forming of aluminum alloy sheets (a) Ultrasonic amplitude $0 \mu \mathrm{m}$ (b) Ultrasonic amplitude $1.3 \mu \mathrm{m}$ (c) Ultrasonic amplitude $6.3 \mu \mathrm{m}$ (d) Ultrasonic amplitude $15.9 \mu \mathrm{m}$.

The effect of the ultrasonic vibration on the roughness surface is also analyzed. The 3D surface topography of samples formed with different ultrasonic amplitude during ultrasonic-assisted incremental sheet forming is shown in Figure 9. The average values and 
square deviation of surface roughness (Sa) with ultrasonic amplitude of $0,1.3 \mu \mathrm{m}, 6.3 \mu \mathrm{m}$, $15.9 \mu \mathrm{m}$ were $0.512( \pm 0.049) \mu \mathrm{m}, 0.287( \pm 0.021) \mu \mathrm{m}, 0.152( \pm 0.012) \mu \mathrm{m}$, and $0.105( \pm 0.008)$ $\mu \mathrm{m}$, respectively. Obviously, the values of the roughness decreased with the continuous increase of ultrasonic amplitude. The reason is that the high-frequency impact caused by the ultrasonic vibration can rearrange the surface texture, and generates a more uniform roughness surface, resulting in the reduction of the roughness value.

Two-dimensional profiles along the feed direction and perpendicular to the feed direction were measured to further explore the influence of ultrasonic vibration on the surface topography, as illustrated in Figure 10. The peak of the two-dimensional profile represents the top of the wave. It can be observed that the peak of the two-dimensional profile with ultrasonic vibration is gentler than that without ultrasonic vibration for the reciprocating movement of the forming tool flats the sharp ridges after the ultrasonic vibration is applied.
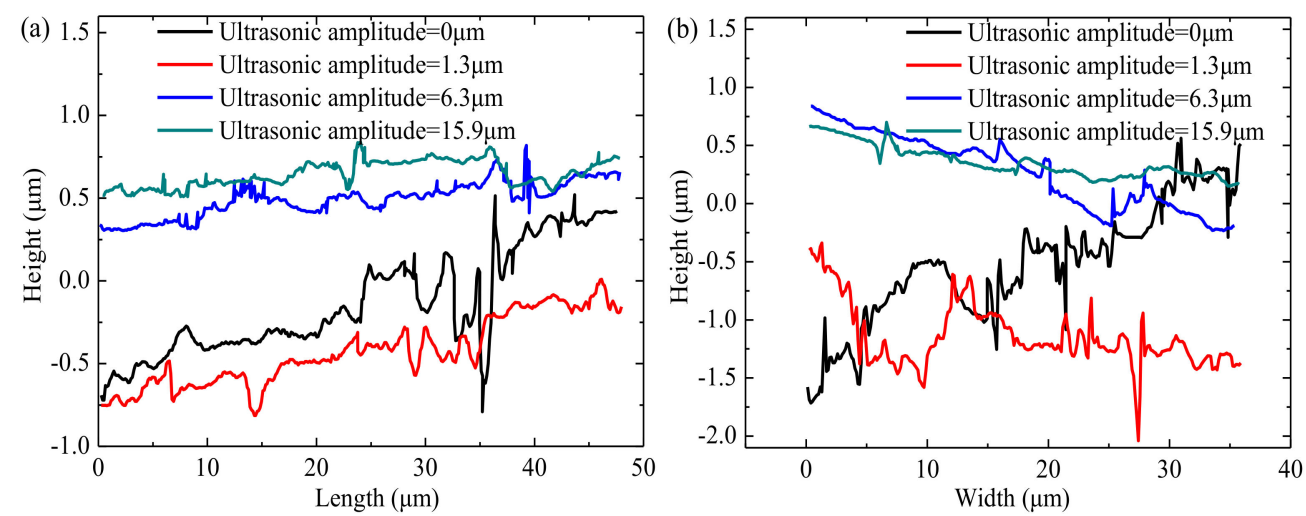

Figure 10. The two-dimensional profiles with different ultrasonic amplitude during ultrasonicassisted incremental sheet forming of aluminum alloy sheets (a) Along the feed direction (b) Perpendicular to the feed direction.

\subsection{Measurement of Surface Hardness}

The measurement results of surface hardness with different ultrasonic amplitude during ultrasonic-assisted incremental sheet forming of aluminum alloy sheets are shown in Figure 11, which indicate that the hardness of the sheet increases greatly compared to the initial hardness $(65 \mathrm{HV})$ after incremental sheet forming. The reason for this phenomenon is the strain hardening phenomenon caused by the plastic deformation of the sheet. Based on the equation of Vickers hardness, the indentation depths of the indenter were calculated to be within $7.3 \mu \mathrm{m} \sim 8.9 \mu \mathrm{m}$ with different ultrasonic amplitudes. Therefore, the results could reflect the hardness value of surface layer of the samples.

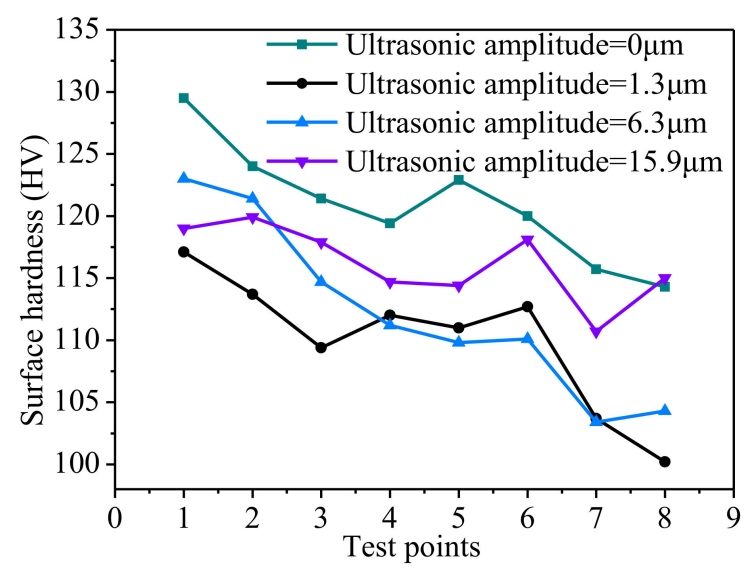

Figure 11. Surface hardness with different ultrasonic amplitude. 
In addition, the application of ultrasonic vibration can reduce the hardness of the contact surface with different ultrasonic amplitude during ultrasonic-assisted incremental sheet forming of aluminum alloy sheets. This is because the application of ultrasonic energy causes the grain to slip, reduces the energy barrier of dislocation movement, thus increases the surface grain size, and promotes dislocation movement, which leads to the decrease of surface hardness [21]. The forming tool in high frequency vibration is passed to the sheet, and the intermittent contact between the forming tool and sheet after applying ultrasonic vibration, tiny deformation and the springback of sheet takes place continuously, which produce a great vibration stress inside of the sheet to offset the original internal stress of the sheet, so that the ability of sheet resistance to external force is weakened, hardness is reduced.

\section{Conclusions}

In the present work, the effects of ultrasonic vibration on the surface property and springback effect during incremental sheet forming of aluminum alloy sheets are investigated by means of reasonable experiments and testing methods. The main conclusions are drawn as follows:

(1) The application of ultrasonic vibration can reduce the springback effect.

(2) The waviness feature of the contact surface becomes gradually weaker and surface roughness decreases with the continuous increase of ultrasonic amplitude due to the high-frequency impact of the forming tool applied ultrasonic vibration.

(3) The application of ultrasonic vibration can reduce the surface hardness and promote the surface residual stress distribution to be more uniform to a certain extent.

Although positive effects of the ultrasonic vibration are experimentally observed, the present work still has limitations: (1) Since the limitation of the testing device, there is a lack of the investigation of ultrasonic vibration on forming force, the uniformity of the thickness and temperature variation; (2) The mechanism study of variations of surface residual stress with and without ultrasonic vibration is not investigated. Therefore, further efforts could be focused on the effects of ultrasonic vibration on the forming force, the uniformity of the thickness, temperature variation and microscopic changes of ultrasonic-assisted incremental sheet forming.

Author Contributions: Y.S. wrote the manuscript; Z.L. and C.L. achieved experiments, data analysis, and investigation; R.W. assisted with experiments; W.Z. assisted with review. All authors have read and agreed to the published version of the manuscript.

Funding: This work was supported by the International Cooperation Research Project of Qilu University of Technology (Shandong Academy of Sciences) (QLUTGJHZ2018006), the National Natural Science Foundation of China under Grant (52075275, 51905287), the College Students Innovation and Entrepreneurship Training Program of Shandong Province (S201910431040) and the Young Doctoral Cooperative Foundation of Qilu University of Technology (Shandong Academy of Sciences) (2018BSHZ0010).

Data Availability Statement: Not applicable.

Acknowledgments: The authors would like to thank Mark Li, Conprofe Green Tools Co., Ltd., for his assistance in equipment of ultrasonic transducer and amplitude transformer.

Conflicts of Interest: The authors declare no conflict of interest.

\section{References}

1. Kumar, A.; Gulati, V. Experimental investigation and optimization of surface roughness in negative incremental forming. Measurement 2019, 131, 419-430. [CrossRef]

2. Jackson, K.P.; Allwood, J.M.; Landert, M. Incremental forming of sandwich panels. J. Mater. Process. Technol. 2007, 204, 290-303. [CrossRef]

3. Malhotra, R.; Xue, L.; Belytschko, T.; Cao, J. Mechanics of fracture in single point incremental forming. J. Mater. Process. Technol. 2012, 212, 1573-1590. [CrossRef] 
4. Li, Y.L.; Zhai, W.D.; Wang, Z.J.; Li, X.Q.; Sun, L.L.; Li, J.F.; Zhao, G.Q. Investigation on the material flow and deformation behavior during ultrasonic-assisted incremental forming of straight grooves. J. Mater. Res. Technol. 2020, 9, 433-454. [CrossRef]

5. Ashida, Y.; Aoyama, H. Press forming using ultrasonic vibration. J. Mater. Process. Technol. 2007, 187-188, 118-122. [CrossRef]

6. Hung, J.C.; Tsai, Y.C.; Hung, C. Frictional effect of ultrasonic-vibration on upsetting. Ultrasonics 2007, 6, 277-284. [CrossRef] [PubMed]

7. Siddiq, A.; El Sayed, T. Ultrasonic-assisted manufacturing processes: Variational model and numerical simulations. Ultrasonics 2012, 52, 521-529. [CrossRef] [PubMed]

8. Siu, K.W.; Ngan, A.H.W.; Jones, I.P. New insight on acoustoplasticity Ultrasonic irradiation enhances subgrain formation during deformation. Int. J. Plast. 2011, 27, 788-800. [CrossRef]

9. Dutta, R.K.; Petrov, R.H.; Delhez, R.; Hermans, M.J.M.; Richardson, I.M.; Böttger, A.J. The effect of tensile deformation by in situ ultrasonic treatment on the microstructure of low-carbon steel. Acta Mater. 2013, 61, 1592-1602. [CrossRef]

10. Yao, Z.H.; Kim, G.Y.; Wang, Z.H.; Faidley, L.; Zou, Q.Z.; Mei, D.Q.; Chen, Z.C. Acoustic softening and residual hardening in aluminum: Modeling and experiments. Int. J. Plast. 2012, 39, 75-87. [CrossRef]

11. Edward, L. Apparatus and Process for Incremental Dieless Forming. US38850764A, 19 September 1967.

12. Kitazawa, K.; Wakabayashi, A.; Murata, K.; Yaejima, K. Metal-flow phenomena in computerized numerically controlled incremental stretch-expanding of aluminum sheets. J. Jpn. Inst. Light Met. 1996, 46, 65-70. [CrossRef]

13. Duflou, J.R.; Habraken, A.-M.; Cao, J.; Malhotra, R.; Bambach, M.; Adams, D.; Vanhove, H.; Mohammadi, A.; Jeswiet, J. Single point incremental forming: State-of-the-art and prospects. Int. J. Mater. Form. 2018, 11, 743-773. [CrossRef]

14. Trzepieciński, T.; Kubit, A.; Dzierwa, A.; Krasowski, B.; Jurczak, W. Surface finish analysis in single point incremental sheet forming of rib-stiffened 2024-T3 and 7075-T6 alclad aluminium alloy panels. Materials 2021, 14, 1640. [CrossRef] [PubMed]

15. Zhai, W.D.; Li, Y.L.; Cheng, Z.N.; Sun, L.L.; Li, F.Y.; Li, J.F. Investigation on the forming force and surface quality during ultrasonic-assisted incremental sheet forming process. Int. J. Adv. Manuf. Technol. 2020, 106, 2703-2719. [CrossRef]

16. Naghdi Sedeh, M.R.; Ghaei, A. The effects of machining residual stresses on springback in deformation machining bending mode. Int. J. Adv. Manuf. Technol. 2021, 114, 1087-1098. [CrossRef]

17. Mirnia, M.J.; Dariani, B.M.; Vanhove, H.; Duflou, J.R. Thickness improvement in single point incremental forming deduced by sequential limit analysis. Int. J. Adv. Manuf. Technol. 2014, 70, 2029-2041. [CrossRef]

18. Kim, T.J.; Yang, D.Y. Improvement of formability for the incremental sheet metal forming process. Int. J. Mech. Sci. 2000, 42, 1271-1286. [CrossRef]

19. Ingarao, G.; Ambrogio, G.; Gagliardi, F.; Lorenzo, R.D. A sustainability point of view on sheet metal forming operations: Material wasting and energy consumption in incremental forming and stamping processes. J. Clean. Prod. 2012, 29-30, 255-268. [CrossRef]

20. Zhang, S.; Tang, G.H.; Li, Z.; Jiang, X.K.; Li, K.J. Experimental investigation on the springback of AZ31B Mg alloys in warm incremental sheet forming assisted with oil bath heating. Int. J. Adv. Manuf. Technol. 2020, 109, 535-551. [CrossRef]

21. Deshpande, A.; Hsu, K. Acoustic energy enabled dynamic recovery in aluminium and its effects on stress evolution and post-deformation microstructure. Mater. Sci. Eng. A 2018, 711, 62-68. [CrossRef] 